\title{
Development of a System for Measuring Micro Hole Accuracy Using an Optical Fiber Probe*
}

\author{
Hiroshi MURAKAMI**, Akio KATSUKI***, Hiromichi ONIKURA***, \\ Takao SAJIMA***, Norio KAWAGOISHI**** and Eiji KONDO**** \\ **Department of Mechanical Engineering, Faculty of Engineering, Kyushu Sangyo University \\ 3-1 Matsukadai 2-chome, Higashi-ku, Fukuoka, 813-8503, Japan \\ E-mail: murakami@ip.kyusan-u.ac.jp \\ *** Depatment of Mechanical Engineering, Faculty of Engineering, Kyushu University \\ 744 Motooka, Nishi-ku, Fukuoka, Japan

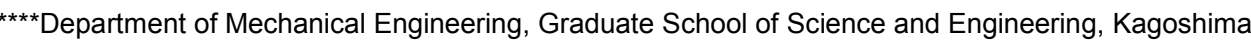 \\ University \\ 1-21-40 Koorimoto, Kagoshima, 890-0065, Japan
}

\begin{abstract}
This paper presents a system for measuring micro holes that makes use of an optical fiber probe. The optical fiber probe is deflected when it comes into contact with a hole surface, and this deflection is measured optically. For this research, the optical fiber probe is fabricated by using an acid etch technique and its characteristics in the process of displacement detection are described. The effects of surface force are then evaluated. The diameter of the optical fiber probe sphere at the tip of the probe is calibrated by using a $1 \mathrm{~mm}$ gage block, and the effect of the probe sphere diameter is compensated for measurement of the roughness standard specimen. As a result, it is confirmed that the accuracy after compensation of the roughness standard specimen as measured by the measuring system corresponds well to that of the surface roughness tester in both shape and value, demonstrating the utility of this means of calibration.
\end{abstract}

Key words: Micro Hole, Deep Hole, Measurement, Optical Fiber Probe, Laser Diode, Accuracy

\section{Introduction}

In recent years, there has been an increasing demand for a method to measure the accuracy of micro holes in fuel injector nozzles, chemical fiber spinning nozzles, optical fiber ferrules, medical devices, and the like. It is very difficult, however, to precisely measure the shape of a micro hole that has a large length/diameter $(L / D)$ ratio.

Micro holes have conventionally been measured using optical microscopes due to the demands of the process. This method, however, cannot evaluate the roundness, straightness, cylindricity, and surface roughness of the inside of holes because optical microscopes can measure only the shape of a hole's inlet and outlet. Cross-sectional observation allied to a destructive mode of inspection has been used to measure the internal shape of holes, but this method has the disadvantage of rendering the workpiece unusable after inspection. A means of non-destructive inspection is therefore needed not to scratch the surface of the workpiece. A probe with a small diameter, large aspect ratio and low force is necessary to make possible the precise measurement of micro holes.

Many studies have been reported on micro hole measurement techniques that employ a

${ }^{*}$ Received 15 Feb., 2010 (№. 10-0084) [DOI: 10.1299/jamdsm.4.995]

Copyright $@ 2010$ by JSME 
variety of probes, such as optical probes, vibroscanning probes, vibrating probes, tunneling effect probes, opto-tactile probes, fiber deflection probes, optical trapping probes, diaphragm probes [1-15], among others. This paper presents a system of micro hole measurement using an optical fiber probe that is available as a low-force displacement probe and has a wide measuring range [16]. It is also easy to fabricate a probe with a diameter smaller than $10 \mu \mathrm{m}$ and an aspect ratio larger than 100 . The shaft of such a probe is not necessary to be rigid in order to detect measuring force because its deflection is measured by a non-contact method. In this research, the optical fiber probe is fabricated by using an acid etch technique and the probe's characteristics in the process of displacement detection are described. The effects of surface force are then evaluated. The diameter of a probe sphere is calibrated using a $1 \mathrm{~mm}$ gage block, and the effect of the probe sphere diameter is corrected for measurement of the roughness standard specimen.

\section{Principles of Measurement}

Figure 1 shows an illustration of the optical system and a photograph of the fiber probe. The fiber probe consists of a probe shaft (optical fiber) and probe sphere with diameters of 30 and $50 \mu \mathrm{m}$, respectively. The system is composed of the fiber probe, two floodlighting fibers (FPX, FPY), and two double-light reception fibers (FX1, FX2, FY1, FY2) in the X and $\mathrm{Y}$ directions. The fiber probe is installed between the floodlighting fibers and the light reception fibers in orthogonal positions. The two floodlighting fibers, which are connected to laser diode, are used for irradiation of the laser beam around the fiber probe. The stem of the probe is irradiated by a laser beam emitted by the two floodlighting fibers in the $\mathrm{X}$ and $\mathrm{Y}$ directions. The two double-light reception fibers that are connected to four photo diodes are opposite to the floodlighting fibers. The laser beams that penetrate the probe are received in the two double-light reception fibers. The intensities detected by the four photo diodes are converted into voltage values that are defined as $I_{F X 1}, I_{F X 2}, I_{F Y 1}$, and $I_{F Y 2}(\mathrm{~V})$.

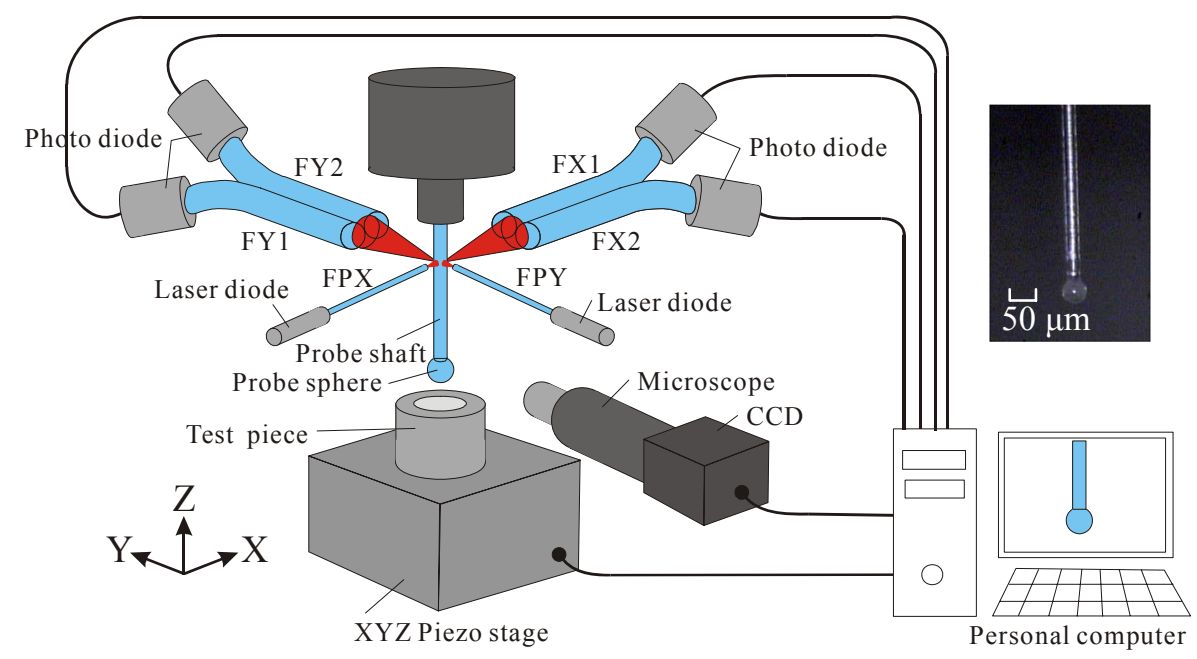

Figure 1: Optical system and photograph of the fiber probe

Figure 2 shows the principles that govern the measurement process. When the probe sphere is not in contact with a hole surface, the light intensity measured by the two double photo diodes is equal $\left(I_{F X I}=I_{F X 2}, I_{F Y I}=I_{F Y 2}\right)$, as shown in Figure 2 (a). When the probe sphere comes into contact with a hole surface (X direction), the probe shaft is displaced and the light intensity of the two double photo diodes becomes unequal $\left(I_{F X I}=I_{F X 2}, I_{F Y I}>I_{F Y 2}\right)$, as shown in Figure 2 (b). Additionally, when the probe sphere comes into contact with a 
hole surface ( $\mathrm{Y}$ direction), the probe shaft is displaced and the light intensity of the two double photo diodes becomes unequal $\left(I_{F X I}>I_{F X 2}, I_{F Y I}=I_{F Y 2}\right)$, as shown in Figure 2 (c). As a result, the direction of contact can be ascertained.

The displacement of the fiber probe is magnified by using it as a rod lens. The surface of the micro hole is scanned in the $\mathrm{Z}$ direction using the precision stage, and the accuracy of the micro hole is measured by recording the contact coordinates and the displacement of the fiber probe.

Output signal $I_{X}$ in the $\mathrm{X}$ direction using $I_{F Y 1}$ and $I_{F Y 2}$, and output signal $I_{Y}$ in the $\mathrm{Y}$ direction using $I_{F X I}$ and $I_{F X 2}$, are defined by Equations (1) and (2), respectively.

$$
\begin{aligned}
& I_{X}=I_{F Y 1}-I_{F Y 2} \\
& I_{Y}=I_{F X 1}-I_{F X 2}
\end{aligned}
$$

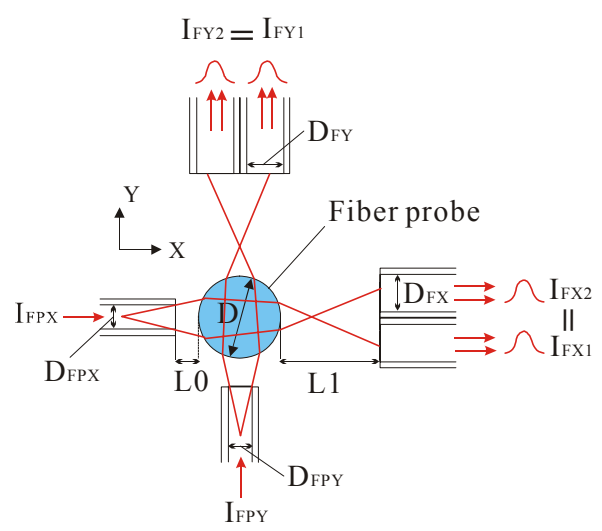

(a) Initial state

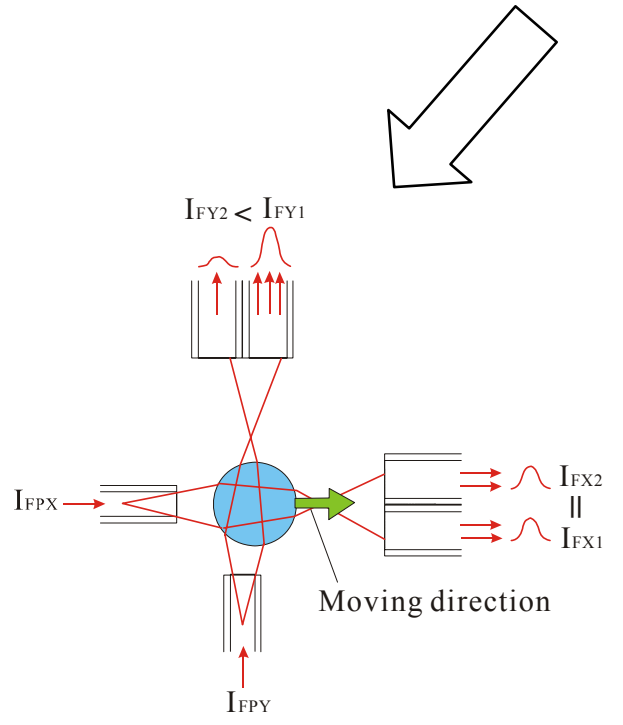

(b) X displacement
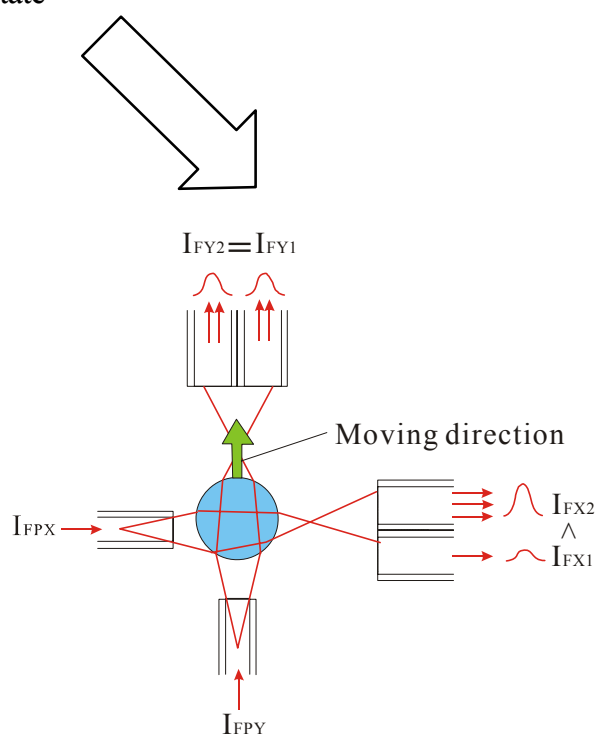

(c) Y displacement

Figure 2 : Measurement principle

\section{Fabrication of the Optical Fiber Probe}

\subsection{Probe shaft}

The optical fiber probe was fabricated using an acid etch technique. First, the step index multi-mode optical fibers (core diameter : $100 \mu \mathrm{m}$, clad diameter : $125 \mu \mathrm{m}$ ) were stripped of their plastic layers. The fibers were then immersed in a $25 \%$ hydrofluoric acid solution, and hydrofluoric acid etching was carried out at room temperature (27 degrees). The diameter of 
the probe shaft was measured with an optical microscope (magnification $50 \times$ ). Figure 3 shows schematics of the probe shaft at three different stages of the hydrofluoric acid etching process. After hydrofluoric acid etching, the probe shaft was rinsed with water and acetone. Figure 4 shows the experimental results. The horizontal axis shows the etching time, and the vertical axis shows the diameter of the probe shaft.

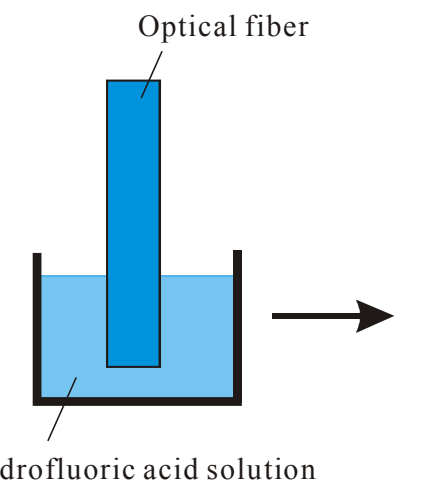

(a) Initial stage (b) Intermediate stage after a few hours

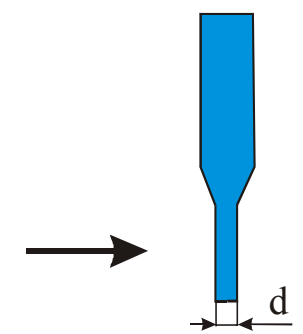

(c) Final stage after etching

Figure 3 : Probe shaft during the hydrofluoric acid etching

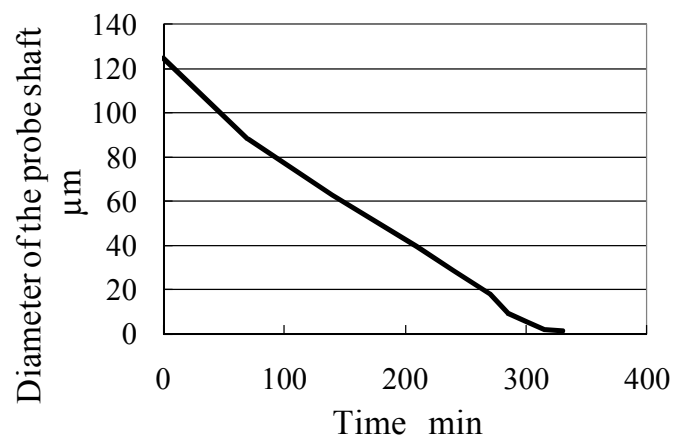

Figure 4 : Relationship between the etching time and diameter of the probe shaft

\subsection{Probe sphere}

After fabricating the probe shaft, the shaft's tip was immersed in ultraviolet curing resin and then moved into contact with the probe sphere which is made of glass. Next, the probe shaft and sphere are irradiated by ultraviolet rays and glued together. Figure 5 shows a photograph of the fiber probe. Figure 5 (a) shows a probe shaft of $30 \mu \mathrm{m}$ in diameter with a probe sphere of $50 \mu \mathrm{m}$ in diameter. This fiber probe is used in the later experiments. Figure 5 (b) shows a probe shaft of about $3 \mu \mathrm{m}$ in diameter with a probe sphere of $5 \mu \mathrm{m}$ in diameter.

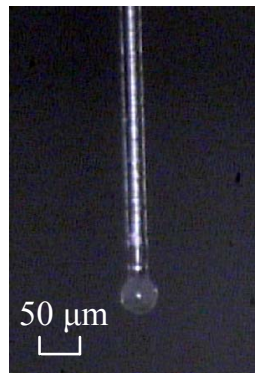

(a) Probe shaft $\phi 30 \mu \mathrm{m}$ and sphere $\phi 50$

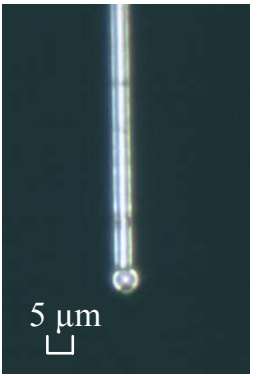

(b) Probe shaft $\phi 3 \mu \mathrm{m}$ and sphere $\phi 5 \mu \mathrm{m}$

Figure 5 : Photograph of the fiber probe 


\section{Characteristics of the Probe during Displacement Detection}

Figure 6 shows the changes in $I_{X}$ and $I_{Y}$ when the probe sphere was displaced in the $\pm \mathrm{X}$ direction. $I_{X}$ and $I_{Y}$ were experimentally obtained. The horizontal axis shows the displacement of the fiber probe, and the vertical axis shows the changes in $I_{X}$ and $I_{Y}$. It was confirmed that $I_{Y}$ only changes slightly when the probe sphere is displaced in the $\mathrm{X}$ direction, and that the fiber probe is available as a displacement sensor because the rate of change of $I_{X}$ can approximate a straight line within a range of $\pm 4 \mu \mathrm{m}$ in the $\mathrm{X}$ direction.

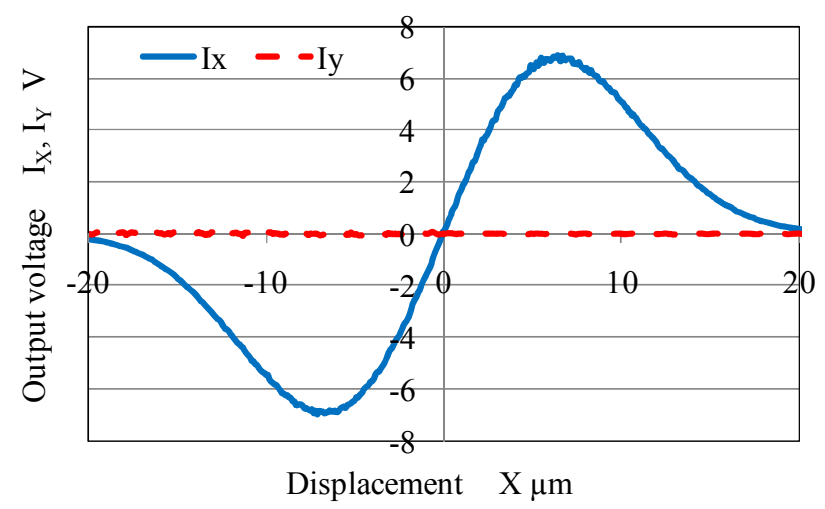

Figure 6 : Output voltage $I_{X}, I_{Y}$ induced by the X-displacement

\section{Effects of Surface Force}

In general, when the particle size is less than several $10 \mu \mathrm{m}$, the effects of surface force due to the intermolecular force, electrostatic force and liquid bridge force are strengthened and become greater than the force of gravity [17]. Because we used a fiber probe with a 50 $\mu \mathrm{m}$ diameter sphere on its tip, we found that the measured surface draws the probe sphere closer when the probe sphere approaches it and the distance between the probe and the surface is less than the regular displacement. When the probe and the measured surface contact each other, the probe adheres to the measured surface and they cannot be separated. There is no reproducibility in the adhesion, which is influenced by the environment (e.g., humidity, temperature) and surface roughness of the measured plane.

Another experiment was then carried out to investigate the effect of the adhesion force. Figure 7 shows the experimental apparatus that was used to evaluate the adhesion force. The change of an output signal $I_{X}$ in the $\mathrm{X}$ direction was measured when the measured surface approached the probe in the $+\mathrm{X}$ direction and was separated from the probe in the -X direction (reciprocating motion).

Figure 8 shows the results of these measurements, which are as follows. (1)The output voltage does not change when the distance $d$ between the probe sphere and the measured surface is more than the displacement of $0.1 \mu \mathrm{m}$. (2) The probe sphere is drawn and adhered to the measured surface, when the former approaches latter and the distance $d$ is less than $0.1 \mu \mathrm{m}$. The output voltage $I_{X}$ expresses a negative value because the probe sphere is displaced in the $-\mathrm{X}$ direction. (3) Next, the output voltage $I_{X}$ returns to the initial state when distance $d$ is 0 . (4)Then, output voltage $I_{X}$ increases because the probe sphere is displaced keeping contact with the measured surface. Because the effect of the surface force is not negligible in the measurement of a microstructure, we need a method of measurement that takes surface force into consideration. However, a force greater than the surface force is required to separate the probe sphere which adheres to a measured surface from that surface (6). 

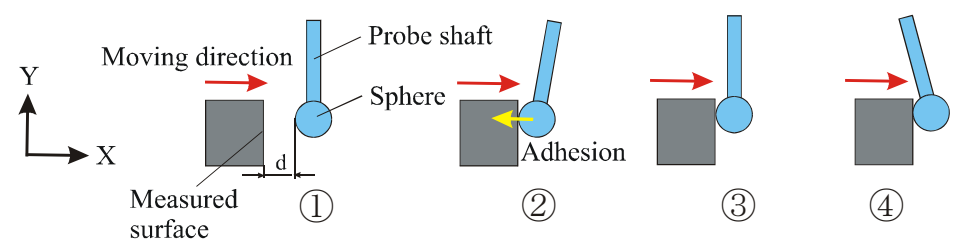

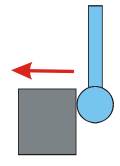

(5)

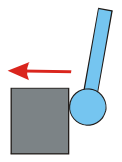

(6)

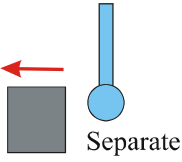

(7)

Figure 7 : Experimental apparatus for examining the adhesion force

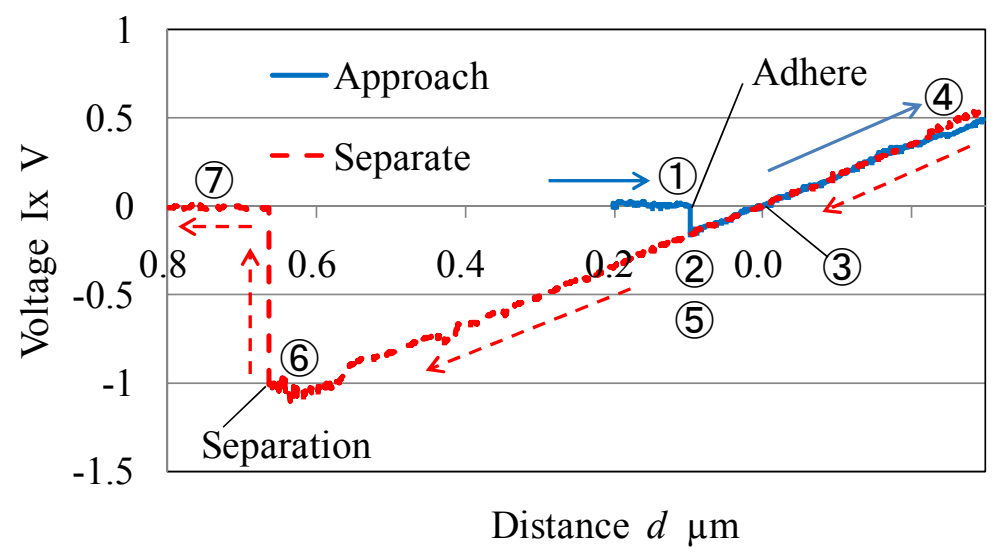

Figure 8 : Output voltage $\mathrm{I}_{\mathrm{X}}$ induced by the $\mathrm{X}$-displacement (reciprocating motion)

\section{Calibration of Probe Sphere}

\subsection{Probe sphere diameter}

The probe sphere is made from glass and its diameter is about $50 \mu \mathrm{m}$ (NIST traceable mean diameter : $49.9 \pm 3.0 \mu \mathrm{m}$ ). However the diameter is calibrated using a $1 \mathrm{~mm}$ gage block for its precise measurement. The tilt of the gage block is compensated for by measuring the several points on both sides of the gage block. The difference of the measured length and the gage block length gives the diameter of the probe sphere in the $\mathrm{X}$ direction. The measured diameter of the probe sphere was $50.56 \mu \mathrm{m}$.

\subsection{Compensation for the shape of the probe sphere}

Because the shape measured using this system corresponds to the path of the ball's center, its shape is different from that of the contact point path. A measurement experiment using a roughness standard specimen $(R a=2.94 \mu \mathrm{m}, R z=9.3 \mu \mathrm{m})$ was therefore performed to investigate the effect of the shape of the probe sphere. To make a comparison, the roughness standard specimen was measured by using both this measuring system and a commercial surface roughness tester (CS-5000, Mitutoyo).

Figure 9 shows the experimental apparatus used to measure the roughness standard specimen in touch trigger mode. The specimen was displaced in the $-\mathrm{X}$ direction by the XYZ precision piezoelectric stage so that output signal $I_{X}$ or $I_{Y}$ was equal to the threshold value $(0.015 \mathrm{~V})$. The coordinates of the stage were then recorded and the roughness standard specimen was displaced by $1 \mu \mathrm{m}$ step in the $-\mathrm{Z}$ direction. This operation was carried out repeatedly, to ascertain the shape of the roughness standard specimen. Considering the effect of the surface force, as mentioned above, the specimen fixed by the stage was fed at a rate of about $10 \mu \mathrm{m} / \mathrm{s}$ in the $-\mathrm{Z}$ direction. If the specimen was fed in the $\mathrm{X}$ and $\mathrm{Y}$ directions, the probe shaft would be deflected by the surface force and the measurement accuracy 


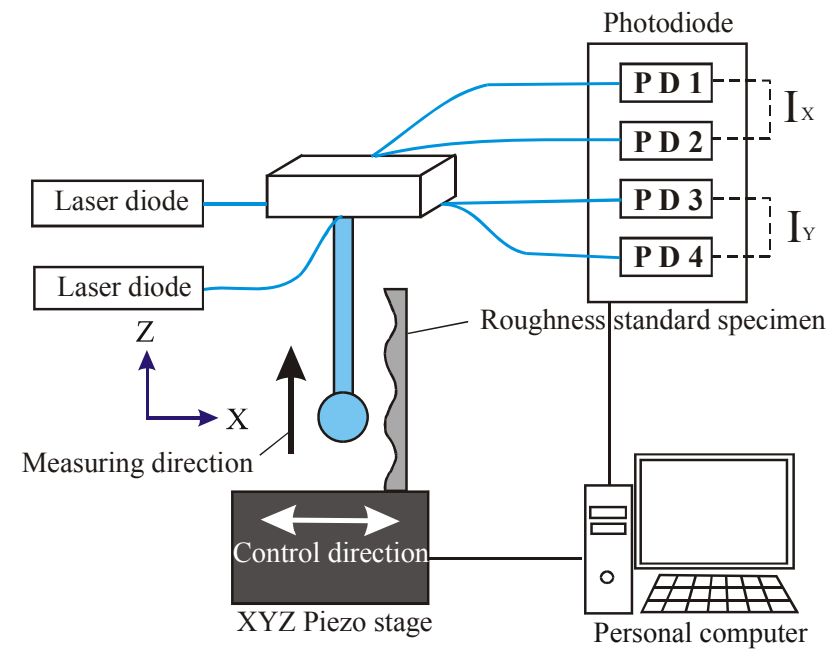

Figure 9: Experimental apparatus used to measure the roughness standard specimen

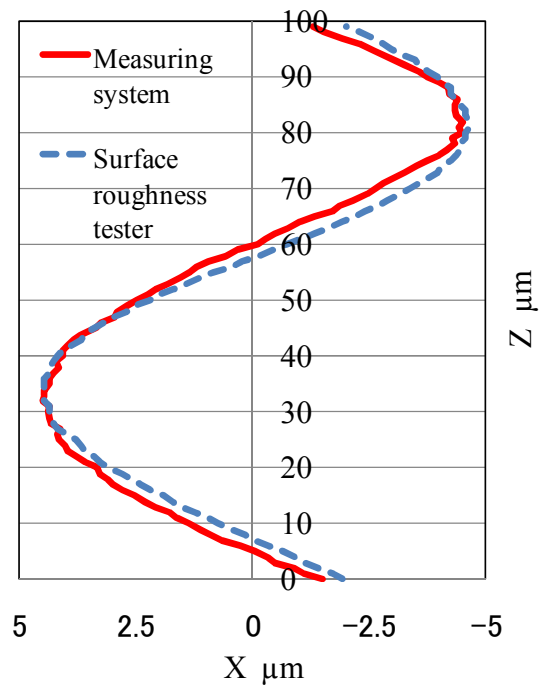

Figure 10: Comparison of the cross-sectional shapes of the roughness standard specimen measured by a surface roughness tester and the measuring system (Before probe-radius compensation)

would decrease greatly. The measuring data were acquired at a sampling interval of $1 \mu \mathrm{m}$. The measured length was $100 \mu \mathrm{m}$ due to the limitations of the stage's range of movement.

Figure 10 shows the measurement results for the roughness standard specimen as measured using both the measuring system and a surface roughness tester.

The shapes of the concave and convex parts are slightly different from the shape of the roughness standard specimen because the diameter of the probe sphere used with the surface roughness tester (radius $=5 \mu \mathrm{m}$ ) was different from that used with the measuring system (radius $=25 \mu \mathrm{m}$ ) shown in Figure 11. When the diameter of the probe sphere is large, the tilt angle of the roughness curve in the shape of convex parts decreases and the angle in the shape of the concave parts increases. Thus, since the diameter of the probe sphere affects the measured shapes, it must be compensated in order to obtain precise measurement results.

Therefore, as shown in Figure 12, the regression line was calculated using the measuring coordinate $\mathrm{P}_{\mathrm{i}}\left(\mathrm{x}_{\mathrm{i}}, \mathrm{y}_{\mathrm{i}}, \mathrm{z}_{\mathrm{i}}\right)$, the front coordinate $\mathrm{P}_{\mathrm{i}-2}\left(\mathrm{x}_{\mathrm{i}-2}, \mathrm{y}_{\mathrm{i}-2}, \mathrm{z}_{\mathrm{i}-2}\right), \mathrm{P}_{\mathrm{i}-1}\left(\mathrm{x}_{\mathrm{i}-1}, \mathrm{y}_{\mathrm{i}-1}, \mathrm{z}_{\mathrm{i}-1}\right)$ and the rear 
coordinate $\mathrm{P}_{\mathrm{i}+1}\left(\mathrm{x}_{\mathrm{i}+1}, \mathrm{y}_{\mathrm{i}+1}, \mathrm{z}_{\mathrm{i}+1}\right), \mathrm{P}_{\mathrm{i}+2}\left(\mathrm{x}_{\mathrm{i}+2}, \mathrm{y}_{\mathrm{i}+2}, \mathrm{z}_{\mathrm{i}+2}\right)$. The normal vector of the regression line was then calculated. Next, the measuring coordinate $\mathrm{P}_{\mathrm{i}}\left(\mathrm{x}_{\mathrm{i}}, \mathrm{y}_{\mathrm{i}}, \mathrm{z}_{\mathrm{i}}\right)$ was moved from the ball center point to the contact point in the direction of the normal vector (moving distance $=$ calibrated radius of the probe sphere: $50.56 / \mathrm{Z} \mu \mathrm{m}$ ). As a result, compensated values are determined.

Figure 13 shows the measurement results for the roughness standard specimen measured using both a surface roughness tester and the measuring system after the diameter of the probe sphere is compensated. Though it is not possible to accurately compare these measurement results since the same part of the roughness standard specimen was not measured, their shapes, wavelengths, and crest values correspond well with each other. The shape of the concave part is slightly different from that of the roughness standard specimen, perhaps because the shape of the probe sphere cannot be compensated well due to the rugged shape of the concave part, as shown Figure 10.

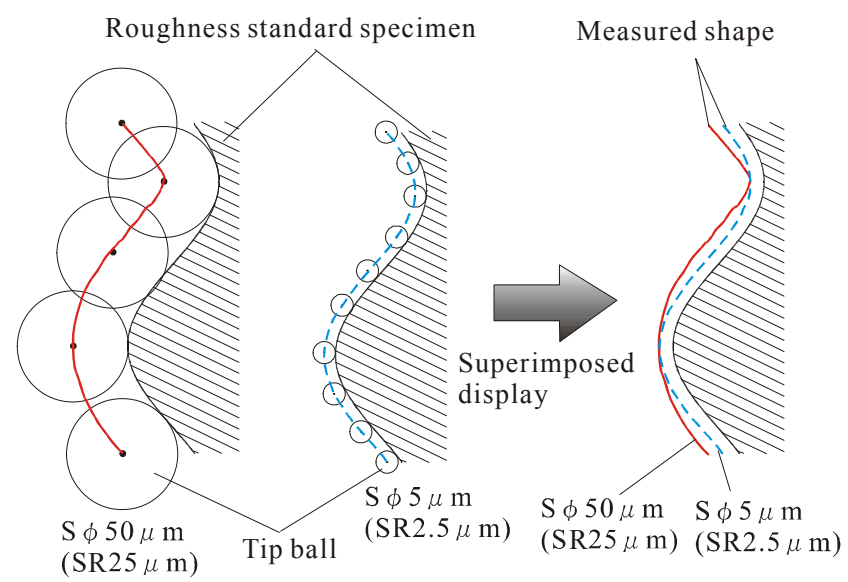

Figure 11: Schematic diagrams of roughness shapes measured by probe sphere of 50 and $10 \mu \mathrm{m}$ in diameter

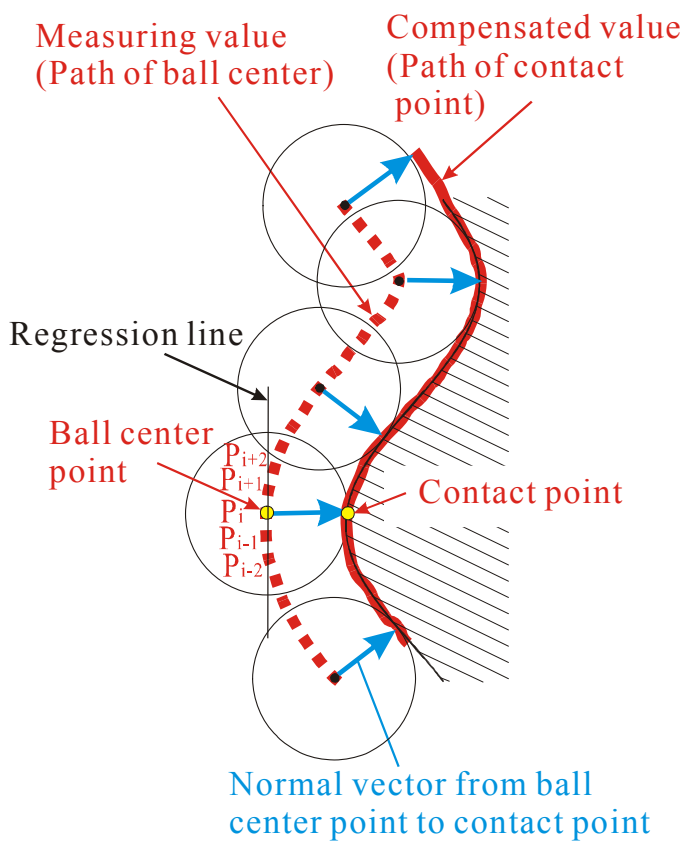

Figure 12: Schematic diagram of the correction method of the effect of the probe sphere diameter

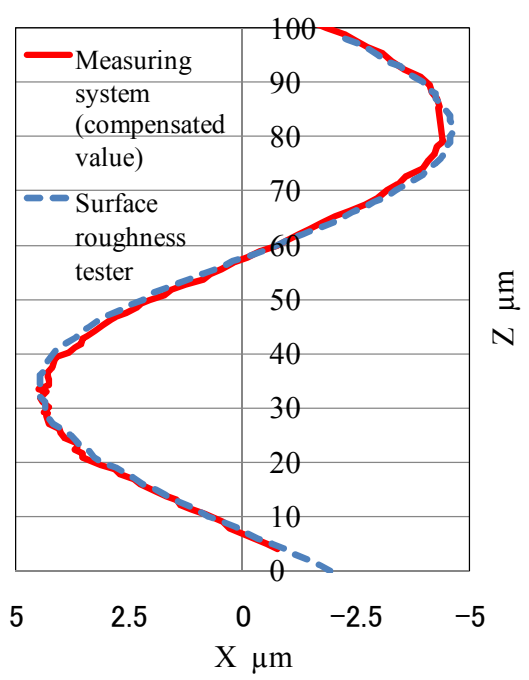

Figure 13: Comparison of the cross-sectional shapes of the roughness standard specimen measured by a surface roughness tester and the measuring system (After probe-radius compensation) 


\section{Conclusion}

We have developed a system for measuring micro hole accuracy using an optical fiber probe. A prototype of the system was fabricated on trial. The optical fiber probe was fabricated using an acid etch technique, and the characteristics of the probe in the process of displacement detection were then described. The effects of the surface force were then evaluated. The diameter of the probe sphere was calibrated using a $1 \mathrm{~mm}$ gage block, and the effect of the probe sphere diameter was corrected for measurement of the roughness standard specimen.

As a result, it was confirmed that the accuracy after correction of the roughness standard specimen measured by the measuring system corresponds well to that of the surface roughness tester in both shape and value, demonstrating the utility of the calibration.

\section{Acknowledgements}

The authors would like to thank Mr. Koichi Ichiki of the Kagoshima Prefectural Institute of Industrial Technology for his technical support in the experiments. This work was supported in part by a Grant-in-Aid for Young Scientists (B) from the Ministry of Education, Culture, Sports, Science and Technology of Japan, a research grant from the Machine Tool Engineering Foundation, and Industrial Technology Research Grant Program in 2009 from New Energy and Industrial Technology Development Organization (NEDO) of Japan.

\section{References}

(1) Maruyama, M., Osaka, H., Ono, M. and Kasei, S., Development of Optical Apparatus for Measuring Small Hole Diameter, Journal of the Japan Society for Precision Engineering, Vol.62, No.1, (1996) pp.145-149 (in Japanese).

(2) Akiyama, N., Kitano, A., Yoshida, M., Fujimoto, E., Kohira, H. and Fukushima, T., Development of an Optical Measurement Equipment for Diameter of Small and Deep Hole, Journal of the Japan Society for Precision Engineering, Vol.62, No.4, (1996) pp.584-588 (in Japanese).

(3) Onikura, H., Kuwabara, Y., Nakamura, T., Sajima, T., Imazeki, Y., Katsuki, A. and Yamada, S., Development of an Optical Hole-Diameter Measurement Instrument - Optical Analysis, Fundamental Experiment, Trial Manufacture and Performance Test -, Journal of the Japan Society for Precision Engineering, Vol.61, No.2, (1995) pp.248-252 (in Japanese).

(4) Masuzawa, T., Hamasaki, Y. and Fujino, M., Vibroscanning Method for Nondestructive Measurement of Small Holes, CIRP Annals, Vol.42, No.1, (1993) pp.589-592.

(5) Masuzawa, T., Kim, B. J., Bergaud, C. and Fujino, M., Twin-Probe Vibroscanning Method for Dimensional Measurement of Microholes, CIRP Annals, Vol.46, No.1, (1997) pp.437-440.

(6) Hidaka, K., Study of a Small-Sized Ultrasonic Probe, CIRP Annals, Vol.55, No.1, (2006) pp.567-570.

(7) Hidaka, K., Saito, A. and Koga, S., Study of a micro-roughness probe with ultrasonic sensor, CIRP Annals - Manufacturing Technology, Vol.57, (2008) pp.489-492.

(8) Bauza, M. B.., Hocken, R. J., Smith, S. T. and Woody, S. C., Development of a Virtual Probe Tip with an Application to High Aspect Ratio Microscale Features, Review of Scientific Instruments, Vol.76, (2005) pp.095112-1-095112-8.

(9) Shiraishi, T. and Mitsui, K., Development of Three Dimensional Profile Measuring Apparatus for Microparts -Measuring Principle and Measuring Results-, Journal of the Japan Society for Precision Engineering, Vol.64, No.9, (1998) pp.1395-1399 (in Japanese).

(10) Shiramatsu, T., Kitano, K., Kawata, M. and Mitsui, K., Development of a Measuring 
Method for Shape and Dimension of Micro-components -Modification to the Original Measuring System, Calibration of the Probes and the Results of Dimensional Measurements-, Journal of the Japan Society of Mechanical Engineers, Series C, Vol.68, No.683, (2002) pp.267-274 (in Japanese).

(11) Schwenke, H., Wäldele, F., Weiskrich, C. and Kunzmann, H., Opto-Tactile Sensor for 2D and 3D Measurement of Small Structures on Coordinate Measuring Machines, CIRP Annals, Vol.50, No.1, (2001) pp.361-364.

(12) Muralikrishnan, B., Stone, J. A. and Stoup, J. R., Fiber deflection probe for small hole metrology, Precision Engineering, Vol.30, (2006) pp.154-164.

(13) Michihata, M., Takaya, Y. and Hayashi, T., Development of the nano-probe system based on the laser-trapping technique, CIRP Annals, Vol.57, (2008) pp.493-496.

(14) Takamasu, K., Chih-Che, K., Suzuki, A., Hiraki, M., Furutani, R. and Ozono, S.., Development of Pneumatic Ball Probe (1st Report) -Basic Construction-, Journal of the Japan Society for Precision Engineering, Vol.64, No.8, (1998) pp.1153-1157 (in Japanese).

(15) Yang, S., Li, S., Kaiser, M. J. and Eric, F. H. K., A probe for the measurement of diameters and form errors of small holes, Measurement Science and Technology, Vol.9, (1998) pp.1365-1368.

(16) Murakami, H., Katsuki, A., Onikura, H., Sajima, T. and Kondo, E., Development of a Micro Hole Measuring System Using an Optical Fiber Probe -Optical Analysis and Accuracy Evaluation-, Journal of the Japan Society for Precision Engineering, Vol.75, No.12, (2009) pp.1476-1481 (in Japanese).

(17) Okuyama, K., Masuda, H. and Morooka, S.; Biryushi Kogaku, Ohmsha, Tokyo, Japan, (1992), pp.32. 